\title{
Tax Innovation under Low-carbon Economy System Xiaoyan Shao
}

AIEN International Institute, Dalian Jiaotong University, Dalian, 116021, China

\author{
Keywords: Low-carbon economy, System, Tax innovation
}

\begin{abstract}
In order to ensure that Chinese economy develops toward the mainstream direction of low-carbon economy, we can exert government-leading function to realize the adjustment of tax revenue on economic development. On the basis of the current situation of Chinese economic development and low-carbon economic construction, this paper explains the concept and essence of low-carbon economic development, analyzes the factors influencing low-carbon economic development in terms of tax revenue, and discusses the specific measures of tax revenue innovation under low-carbon economy system.
\end{abstract}

\section{Introduction}

The low-carbon economy is the trend of economic development of various countries in the world, and it is a brand-new mode of economic development which is related to enterprise production mode, people's lifestyle and values, and national collective interests. The development of low-carbon economy requires that we make full use of multiple measures to develop advanced productivity and eliminate and restrict high energy-consumption, high-pollution, and high-emission enterprise production mode on the basis of certain economic strength and science and technology. As one of effective measures of macro-control of Chinese socialist market economy, the tax revenue can adjust industrial structure and optimize resource configuration, thus it has great potential in promoting Chinese low-carbon economic development. However, it can't be denied that there exist certain problems in Chinese current tax policy as for developing low-carbon economy. Therefore, under low-carbon economy system, the innovation work of tax revenue is very necessary.

\section{Low-carbon economy and its circulation system}

As the name suggests, the low-carbon economy refers to reducing carbon emission in the economic development process, and its essence is to carry out a series of innovation on science, technology, and system to improve efficiency of energy use, establish clean production structure, and reduce environmental pollution and resource waste.

The circulation system of low-carbon economy mainly consists of following three sub-systems. The first one is the import link of energy flow; in this link, we reduce the utilization rate of traditional high-carbon coal, petroleum, natural gas and other high-carbon energy, and use solar energy, bioenergy, wind energy, and other low-carbon renewable clean energy to replace them. The second one is the conversion link of energy flow; in this link, we establish smart power grid and energy internet, and enhance the utilization of various kinds of energy to ensure that each industry develops toward low-carbon direction. The third one is the export link of energy flow; in this link, we enhance the construction of carbon sink such as forest, develop carbon catching and storing technology to enhance the absorbing amount of carbon dioxide in economic construction process and ensure the low-carbon economic development.

\section{Tax bottleneck restricting low-carbon economic development}

Currently, there still exists many problems in China's low-carbon economic development, such as incomplete system construction, enterprise' low enthusiasm in participation, and lack of uniform standard. There are many reasons which cause those problems, and the reasons related to tax revenue include as below: 


\section{The current tax system has weak ability to regulate low-carbon economy.}

Currently, in terms of tax revenue, China mainly depends on various categories of taxes and respective preferential policies to promote the development of low-carbon economy, thus it is hard to exert collective interests and form incentive resultant force. Currently, China has formulated a series of preferential tax policy for low-carbon enterprises. For example, the Ministry of Finance and State Administration of Taxation of the People's Republic of China issued Notice on Integrated Use of Natural Resources and Added-value Tax Policy for Other Products and Notice of China Clean Development Mechanism Foundation and Clean Development Mechanism Project Implementation Enterprises on Problems of Corporate Income Tax Policies in 2008 and 2009 respectively; the first point is to exempt added-value tax for self-produced cargo such as recycled water and retreaded tire, and the second point is to exempt corporate income tax for the fund obtain via some clean projects. Although those preferential policies can exert certain function in relevant fields, it can't be denied that it is hard that the preferential policies distributed in various kinds of taxes can promote the development of low-carbon economy as a whole. Due to this reason, most of enterprises have low enthusiasm in participating in construction of low-carbon economy.

\section{Lack of category of tax which directly controls enterprise and negative external influence of enterprise behavior}

In the production and processing process, many enterprises will cause some negative external influence, such as water pollution, air pollution, and other environmental pollution. Currently, China lacks of the measures of treating those negative external influences, thus the overall environmental management effect and development scale of low-carbon economy remain to be further improved. Here, China shall borrow ideas from foreign measures that they regard tax policies as the means to manage environmental pollution and develop low-carbon economy, and keep a foothold in China's national condition to carry out corresponding reform on tax policies. Through enhancing the punishment, we can establish tax policies with perfect system to control the negative external influence of enterprises.

\section{Lack of uniform tax policy about environmental protection}

According to the content mentioned above, we can know that China has formulated specific preferential tax policy in terms of utilization of renewable resources and environmental protection. However, the tax source of those policies is distributed, thus there lacks of uniform coordination among added-value tax, income tax, consumption tax, and resource tax in terms of promoting low-carbon economic development, thus various kinds of tax revenues cause little stimulation on low-carbon economic development.

\section{No special tax of eco-environment protection is formulated.}

Currently, China has issued many policies in favor of environmental protection in terms of individual income tax, resource tax, added-value tax, and consumption tax, but no special tax of eco-environment protection is formulated. Therefore, there is small function on environmental protection, and various kinds of behaviors of high energy-consumption, high-pollution, and high-emission production are on a rampage. By contrast, some developed countries have perfect tax policies in those aspects. For example, British government levies the tax about climate protection from commercial and public departments which purchase electricity power, coal, and liquefied petroleum gas, and the tax-levying standard is to additionally increase $15 \%$ on the basis of energy source; as for renewable energy source, the government exempts the tax of climate change. Besides, the Swedish government levies carbon tax, and the Netherlandish government levies tax of energy regulation.

\section{Tax innovation measures under low-carbon economy system}

As an important means of regulating socialist market economy in China, the tax has great functions of optimizing resource configuration and regulating industrial structure. Under the 
requirement of Chinese low-carbon economic development, in order to keep the regulating function on economy for a long time, the tax policies which were established in extensive economic development mode have to carry out tax innovation. The specific tax innovation measures can be made from perspective of reforming current tax system and setting new tax of ecological environmental protection.

\section{Reform current tax system}

\section{To perfect corporate income tax}

The energy conservation and emission reduction is an outstanding new requirement in new "law of corporate income tax". For example, it is stipulated in new "law of corporate income tax" that the enterprise which engages in environmental protection which meets the condition and energy and water conservation projects can be exempted from corporate income tax as for its income from business operation and technology transfer; as for new high-tech enterprise under national key support, the tax will be reduced by $15 \%$; in case of "three new development" expense, the tax will be reduced by $50 \%{ }^{(1)}$. Therefore, it can be seen that the tax plays a great role in promoting corporate development under low-carbon economy. Besides, we can perfect the system of corporate income tax from following two aspects.

As for different industry, we can implement different pre-tax deduction standard for corporate income tax. Under the condition of considering Chinese low-carbon economic development, we shall formulate reasonable pre-tax deduction standard for corporate income tax. The pre-tax deduction standard for corporate income tax of high-carbon enterprise can be raised suitably, and the standard for low-carbon enterprise can be reduced accordingly.

With the progress and development in science and technology, in order to make low-carbon enterprises obtain a better development and mitigate the pressure brought by impairment of assets due to technological development, it is able to deduct various kinds of preparation for impairment of assets and loan loss provision withdrawn by low-carbon enterprises.

To perfect individual income tax

Currently, the self-employed personnel is an important part of whole economic system in China, and it can play a great function in managing environmental pollution, improving ecological quality, regulating industrial structure, and optimizing resource configuration; therefore, it is able to set relevant rule of tax credit for individual income tax of self-employed personnel who actively manage environmental pollution.

To perfect added-value tax

Currently, China's added-value tax policies play a certain function in developing low-carbon economy, and the specific function is reflected at following aspects. Firstly, as for common tax-paying enterprises which utilize remaining industrial waste residue and waste materials to carry out cargo production, we implement the tax policy of easy levying and deduction. Secondly, as for enterprises which utilize waste residue and waste materials to carry out production of building materials and utilize wind power generation, the policy of tax halving is implemented. Thirdly, as for enterprises which utilize household refuse to carry out power generation, or utilize the by-products obtained after flue gas desulfurization in thermal power plant to carry out product processing, the policy of tax deduction and exemption is implemented. Finally, as for sewage treatment expense of tap water plant and sales of industrial flue gas and materials, the policy of tax deduction and exemption is implemented. However, it can't be denied that the significance is small. In order to further increase the promotion function of added-value tax on low-carbon economic development, it is able to further expand preferential tax policies for above enterprises. For example, as for common tax-paying enterprises which utilize remaining industrial waste residue and waste materials to carry out cargo production as well as enterprises which utilize waste residue and waste materials to carry out production of building materials, it is able to implement the policy of tax deduction and exemption; as for enterprises which utilize household refuse to carry out power generation, or utilize the by-products obtained after flue gas desulfurization in thermal power plant to carry out product processing, the suitable subsidy is provided. 


\section{To perfect consumption tax}

The consumption tax plays an important role in improving people's awareness of energy conservation and environment protection, and restricting people's resource waste and environmental pollution behavior. For example, the taxes set for wooden disposable chopsticks, solid wood floor, golf, brassie, and petroleum products in recent years in China effectively restrict resource waste and effectively regulate economic development toward low-carbon direction. However, those measures are insufficient to meet the development requirement of low-carbon economy, thus it is required to further perfect consumption tax. The specific measure is to firstly expand the levying scope of consumption tax, which focuses on products produced by use of non-renewable resource and high energy-consumption and high pollution products. Secondly, it is to optimize the tax rate structure of consumption tax. It is required to expand the consumption tax rate of products such as large-displacement automobile, motorcycle, fireworks, and firecrackers and then reduce the tax rate of products which meet the standard of energy conservation and environmental protection. As for products produced by use of non-renewable resource and high energy-consumption and high pollution products, it is required to levy the tax rate according to sales amount or production amount to enhance the restraint and control on non-low-carbon economy. Besides, as for automobile with same gas displacement, the consumption tax will be levied based on whether the exhaust purifier is installed.

\section{To perfect resource tax}

Currently, China's resource tax is only levied toward 7 kinds of resources including crude oil, natural gas, coal, raw ore of black metal mine, raw ore of nonferrous metals ore, and salt, etc., and some natural resources are not included in scope of levying. As a whole, China's levying mode of resource tax is single and easy. Therefore, we shall expand the scope of levying resource tax, and include the natural resources which need protection, especially deficient natural resources, into levying scope. Besides, according to property of resource, we can adopt different way of levying, such as tax levying based on amount, tax levying based on price, comprehensive tax levying. As for non-renewable and deficient resources, we shall expand the tax-levying rate of resource tax to protect resource and restrict resource overdevelopment.

To perfect tariff

The tariff plays a vital function in the development of national economy, but it plays little function in environmental protection, thus the tariff levying work requires to be further perfected. The specific measures are shown as below: making statistical and auditing work on materials and products (including semi-finished products) which pollute the environment, and including them into the levying scope of export tax; as for imported materials and products which cause pollution on environment, levying high import surtax; as for equipments used to control pollution or monitor environment, reducing and exempting import tariff; greatly improving the levying tariff for poisonous and harmful chemical products to mitigate the damage caused by those chemical products on China.

\section{Set the tax of ecological environmental protection}

Currently, it is relatively lagging that China makes use of tax policies to regulate low-carbon economic development, and no tax directly related to ecological environmental protection is determined so far. Under the trend of low-carbon economy system, China can make reference to sulfur dioxide tax, noise tax, rubbish tax, battery tax, insecticide tax, and chemical fertilizer tax, etc. set in foreign countries, and set the tax of ecological environmental protection which meets China's national condition. In order to make the measure of setting the tax of ecological environmental protection accepted by people, we can firstly carry out reform in various kinds of environmental protection fees levied in China to realize "fee-to-tax" and include it into the scope of tax of ecological environmental protection. Then, on the basis of "fee-to-tax", we can carry out classification on behaviors and products which cause atmospheric pollution, water pollution, and other pollution in production and life, and then set different tax of ecological environmental protection according to 
classification so as to control pollution, protect ecological environment, and guarantee good economic development.

As an effective measure to promote low-carbon economic development and reduce carbon emission, the carbon tax can be included into the scope of tax of ecological environmental protection. In many foreign countries, they have levied carbon tax and have obtained good effect; therefore, we shall enhance technological research. If it is hard to detect the actual emission of carbon dioxide of each enterprise, it is able to carry out estimate on the emission of carbon dioxide through detecting the using amount of petroleum and coal of each enterprise and then use the estimate as the basis of levying carbon tax.

\section{Conclusion}

The tax plays an important role in promoting economic development, and the development of Chinese low-carbon development can't be separated from tax regulation. Therefore, we shall combine tax construction with low-carbon economic development, carry out tax innovation, reform current tax system via perfecting corporate income tax, individual income tax, resource tax, added-value tax, consumption tax, and tariff, establish special tax of ecological environmental protection to realize tax innovation, and fully exert the regulation function of tax on economic construction to promote low-carbon economic development.

\section{References}

[1] Sun Jie, Li Tong, Shi Junqiao: Research on Tax System Based on Low-carbon Economy, Tax Revenue and Taxation, 2011 (08): 47-48.

[2] Liu Lingya: Low-carbon Economic Development and Tax Innovation, Industry Analysis, 2010 (07): 66-67.

[3] Shen Manhong, He Zhenchuan, Meng Aihong: Innovation of Fiscal Taxation Policy under Perspective of Low-carbon Economy, Journal of Poyang Lake, 2011 (08): 114-115.

[4] Lv Dan, Wang Yan: Innovation of Fiscal Taxation Policy about Promoting Low-carbon Economic Development, Economic Review, 2013 (09): 67-68.

[5] Zhuang Guiyang: Analysis on Paths and Potential of Low-carbon Economic Development of Chinese Economy, Studies in International Technology and Economy, 2005 (07): 23-24. 